\title{
Electronic structures of bisnoradamantenyl and bisnoradamantanyl dications and related species
}

\author{
Caio L. Firme - Tamires F. da Costa • \\ Eduardo T. da Penha • Pierre M. Esteves
}

Received: 12 October 2012 / Accepted: 28 January 2013 /Published online: 28 February 2013

(C) Springer-Verlag Berlin Heidelberg 2013

\begin{abstract}
The highly pyramidalized molecule bisnoradamantene is extremely reactive toward nucleophiles and dienes. In this work, we studied the electronic structure of bisnoaradamantene, as well as those of its cation and dication, which are previously unreported carbonium ions. According to QTAIM and MO analysis, there is a $3 \mathrm{c}-2 \mathrm{e}$ bonding system in the bisnoradamantenyl cation and a $4 \mathrm{c}-2 \mathrm{e}$ bonding system in the bisnoradamantenyl dication. A topological study indicated that, on going from bisnoradamantene to its dication, $\pi$-bond interaction with the bridgehead carbon atom increases. Additional study of the bisnoradamantanyl dication also indicated that it has two multicenter bonding systems. Comparison of the D3BIA and NICS aromaticity indices of these molecules and other derivatives indicates that these indices are well correlated, and analysis of these indices shows that the cationic and dicationic bisnoradamantenyl species are homoaromatic.
\end{abstract}

Electronic supplementary material The online version of this article (doi:10.1007/s00894-013-1785-0) contains supplementary material, which is available to authorized users.

C. L. Firme $(\bowtie) \cdot$ T. F. da Costa

Instituto de Química, Universidade Federal do Rio Grande do

Norte, Av. Salgado Filho, s/n, Lagoa Nova,

Natal, RN, Brazil CEP 59072-970

e-mail: caiofirme@quimica.ufrn.br

C. L. Firme

e-mail: firme.caio@gmail.com

E. T. da Penha $\cdot$ P. M. Esteves

Instituto de Química, Universidade Federal do Rio de Janeiro, Av.

Athos da Silveira Ramos, 149, CT Bloco A, Sala 622,

Cidade Universitária - Ilha do Fundão,

Rio de Janeiro 21941-909, Brazil

Present Address:

E. T. da Penha

Instituto de Química, Universidade Estadual de Campinas,

Campinas, São Paulo, Brazil
Keywords QTAIM · Bisnoradamantenyl dication · Bisnoradamantene $\cdot$ Bisnordamantanyl dication . Carbonium ion

\section{Introduction}

Pyramidalized alkenes are molecules containing $\mathrm{C}=\mathrm{C}$ double bonds in which, for either or both of the $\left(s p^{2}\right)$ unsaturated carbon atoms, the carbon atom lies in a different plane to the three atoms attached to it [1]. The pyramidalization angle $(\Phi)$ is the angle between the axis that passes through both $s p^{2}$ carbon atoms and an atom vicinal to one of those carbon atoms (Scheme 1). Highly pyramidalized alkenes are extremely reactive toward nucleophiles and dienes, which is believed to be due to poor $p-p$ orbital overlap in the double bonds of these systems, which gives these bonds diradical character [2]. The highly pyramidalized and unstable molecule tricyclo[3.3.0.0 $0^{3.7}$ oct-1(5)-ene, or bisnoradamantene 1, was synthesized by Camps and collaborators [3, 4] and Schleyer and collaborators $[5,6]$ (Scheme 1). In the absence of trapping agents, $\mathbf{1}$ dimerizes to its cyclobutane derivative $\mathbf{2}$, which easily converts to the diene derivative 3 . Compounds 2 and $\mathbf{3}$ are the [2+2] cycloaddition and retro-cycloaddition adducts of 1 , respectively.

The most common synthetic applications of bisnoradamantene and its derivatives have been Diels-Alder reactions with reactive dienes, dimerization, and cycloaddition followed by a retro-cycloaddition reaction with another pyramidalized alkene [2, 7-13]. Border et al. successfully detected the $\left(\mathrm{Ph}_{3} \mathrm{P}\right)_{2} \mathrm{Pt}$ complex of the dimethyl derivative of $\mathbf{1}$ [14].

Frontier orbital theory was used by Hrovat and Borden [15] to explain the reactivity of pyramidalized alkenes. As the pyramidalization angle increases, the HOMO/LUMO energy gap decreases and the $\mathrm{C}=\mathrm{C}$ double bond elongates. Greater pyramidalization leads to an increase in the heat of hydrogenation and in the olefin strain energy [2, 15-18]. 

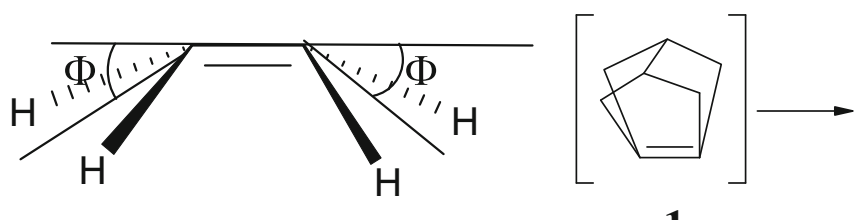

1

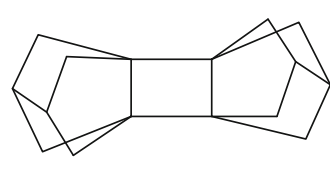

2

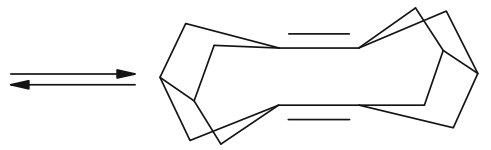

3

Scheme 1 Definition of the pyramidalization angle $(\Phi)$, and dimerization of bisnoradamantene $\mathbf{1}$ to its cyclobutane derivative $\mathbf{2}$ and subsequent conversion to the diene derivative $\mathbf{3}$

However, no theoretical study of the bisnoradamantenyl cation $\mathbf{4}$ and the related dication $\mathbf{5}$ has been performed to date (Scheme 2).

The bisnoradamantenyl cation and dication, the dication derivatives, and the bisnoradamatanyl dication may have multicenter bonding systems that could stabilize such systems. The bisnoradamantenyl dication has similar properties to the 1,3-dehydro-5,7-adamantanediyl dication [19] and related species $[20,21]$. Thus, studying them could lead to strategies for dealing with these unstable systems, and may provide information on the bonding scheme. In this work, we have used the quantum theory of atoms in molecules (QTAIM), the aromaticity indices NICS and D3BIA, and molecular orbital theory to study and compare the electronic structures of these systems with those of their corresponding neutral compounds.

\section{Computational details}

The geometries of the studied species were optimized with the Berny algorithm using energy-represented DIIS in redundant internal coordinates $[22,23]$. Vibrational analysis of the optimized geometries of selected points on the potential energy surface was carried out in order to determine whether the resulting geometries were true minima or transition states by checking for the existence of imaginary frequencies. The calculations were performed at the B3LYP/6-311++G(d,p) [24-26] and M06-2X/6-311++G** [27, 28] levels using the Gaussian 09 package [29]. Electronic density was derived from the Kohn-Sham orbitals and subsequently used in the QTAIM calculations performed by the AIM2000 software package [30]. The algorithm used by AIM2000 to search for critical points is based on the Newton-Raphson method, which is heavily reliant on the starting point chosen [31]. Every available alternative method of increasing the calculation accuracy and choosing different starting points was utilized. Iterations to find critical points begin with nuclear positions, mean values of pairs of maxima, and mean values of triples of maxima, followed by iterations from a chosen starting point that is potentially close to a critical point. Integrations over the atomic basins were calculated in natural coordinates using the default options for integration. All integrations yielded values on the order of $10^{-3}$ to $10^{-4}$ for the Laplacian of the calculated atomic basin. Atomic energies were calculated using the atomic virial approach. All calculated bond paths were mirrored by their

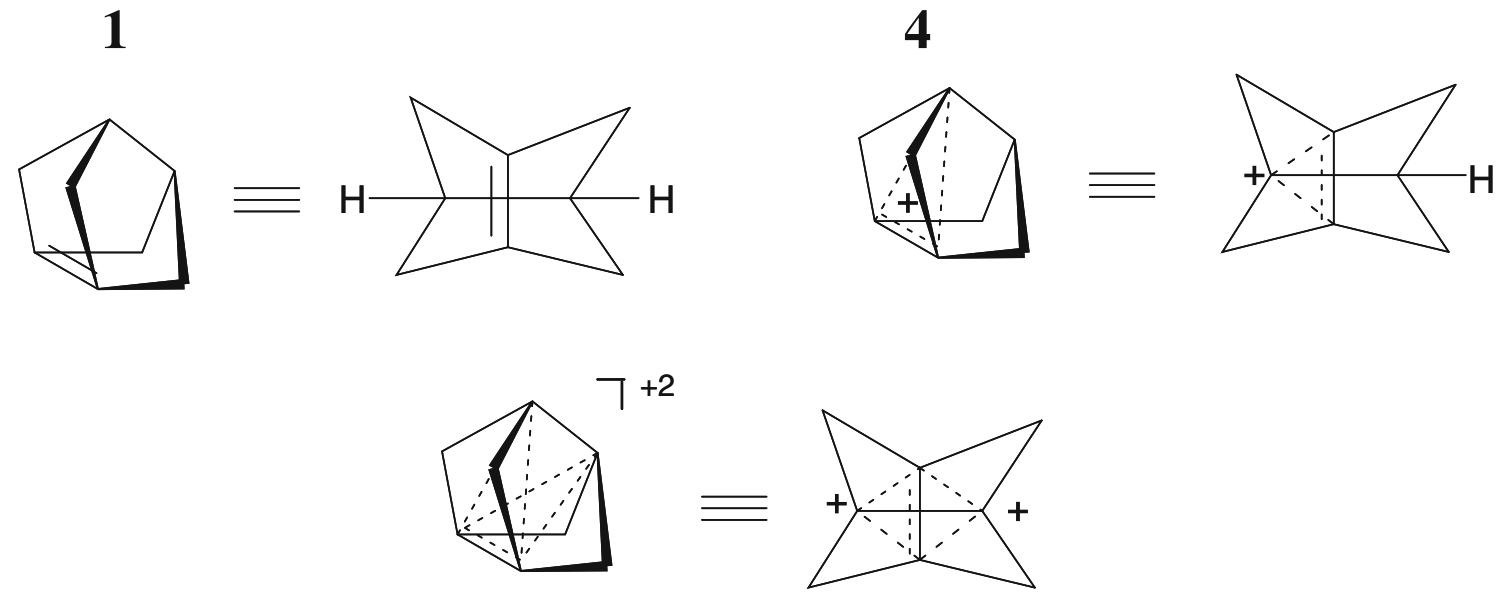

5

Scheme 2 Tridimensional and planarized structures of bisnoradamantene $\mathbf{1}$ and its cation and dication derivatives $\mathbf{4}$ and $\mathbf{5}$, respectively 
corresponding virial paths (i.e., maximum negative potential energy between the two atoms). According to the atomic virial approach, bond paths mirrored by virial paths are indicative of the bonded interaction. All molecular graphs satisfied the Poincaré-Hopf relationship [32], a prerequisite for completeness of the set of critical points of the topology of a given molecular system. MP2(full)/6-311++G** calculations [33] were also performed to obtain the proper MO frontier orbitals. NICS (nucleus-independent chemical shift) calculations [34] were performed at the M06-2X/6-311++G** level by employing the GIAO (gauge-independent atomic orbital) method [35] at the geometric center of the cage.

\section{QTAIM basics}

A critical point is an important point where the first derivative or first partial derivatives (gradient) of a function with respect to its coordinates are zero.

The delocalization index (DI) is the number of electrons shared between each atomic pair [36, 37]. The higher the value of DI, the stronger the (shared shell) interaction between the pair of atoms. On the other hand, the localization index represents the number of electrons localized (not shared) in an atomic basin.

It is important to emphasize that the delocalization index of a very weak $\mathrm{C}-\mathrm{C}$ interaction is on the order of $10^{-2}$ to $10^{-3}$. Moderately strong $\mathrm{C}-\mathrm{C}$ interactions have $\mathrm{DI}$ values on the order of $10^{-1}$ [38-40].

The Laplacian of the charge density is the trace of a Hessian matrix whose elements are second derivatives of the charge density with respect to its coordinates, and it represents the concentration or depletion of the charge density in a specific region of the molecular system [41]. A negative sign for $\nabla^{2} \rho$ represents charge density concentration and a positive sign for $\nabla^{2} \rho$ represents charge depletion.

The ellipticity $(\varepsilon)$ is is calculated as $\left[\left(\lambda_{1} / \lambda_{2}\right)-1\right]$. Here, $\lambda_{1}$ and $\lambda_{2}$ are eigenvalues of the Hessian matrix of the charge density. They are eigenvalues of the corresponding eigenvectors $\vec{u}_{1}$ and $\vec{u}_{2}$, respectively. The eigenvectors $\vec{u}_{1}$ and $\vec{u}_{2}$ belong to a plane perpendicular to the bond path at the BCP between two bonding atoms. When $\varepsilon>0$, the corresponding chemical bond or chemical interaction does not have cylindrical symmetry, unlike a single or triple bond.

\section{D3BIA}

The density, degeneracy, and delocalization-based index of aromaticity (D3BIA) was inspired by the proposal of Nascimento (based on generalized valence bond theory and Feynman diagrams) that the aromaticity of benzene is a 6c-6e multicenter bond [42].
Building on this, we assumed that the degeneracy of the atoms at an aromatic site (for instance, the six carbon atoms in benzene) and the charge density at the aromatic site (for instance, the region inside the benzene ring) are related to the multicenter bonding schemes of aromatic systems (as proposed by Nascimento).

Moreover, we also noticed the influence of the uniformity of the delocalization index over the whole aromatic site on the stability of a chemical species. For example, we observed that the large difference in stability between the (isolated and characterized) 4,9-diamantyl dication and the (yet-to-be-isolated) 1,6-diamantyl dication can be attributed to the higher uniformity of the delocalization indices among the carbon atoms in the former [39]. We therefore proposed the following formula for the delocalization index uniformity (DIU):

$D I U=100-\left(\frac{100 \sigma}{\overline{D I}}\right)$

where $\sigma$ is the mean deviation and $\overline{D I}$ is the mean DI of the aromatic site.

We have performed a more comprehensive study of the importance of the DIU to the stabilities of chemical species, which will be published elsewhere.

After evaluating the topological parameters that may relate to aromaticity - such as the charge density at a cage critical point, the delocalization index, and the atomic energies of carbon atoms at the aromatic (or non-aromatic) sites-for more than 30 aromatic and non-aromatic caged molecules, we arrived at the following formula:

$D_{3} B I A=R D F \cdot \overline{D I} \cdot D I U \cdot \delta$

where $\delta$ is the degree of degeneracy and RDF is the ring density factor. The ring density factor is the charge density of the cage critical point $[\rho(3,+3)]$.

From the analysis of more than 30 aromatic and nonaromatic caged molecules [39], we established that $\delta$ is maximal $(\delta=1)$ when the atomic energy difference at the aromatic site is smaller than 0.009 a.u.

In this work, the degree of degeneracy relates to the $\mathrm{C} 1-$ $\mathrm{C} 4$ atomic basins; $\overline{D I}$ is the average delocalization index for the $\mathrm{C} 1-\mathrm{C} 4$ atomic basins, and the ring density factor is the charge density of the cage critical point $[\rho(3,+3)]$ for topological caged structures, as also established for adamantanediyl ions and their analogs [39].

\section{Results and discussion}

Scheme 3 shows bisnoradamantene 1, the bisnoradamantenyl cation $\mathbf{4}$ and dication $\mathbf{5}$, the dication derivatives 6-8, bisnoraradamantane 9, and the bisnoradamatanyl dication 


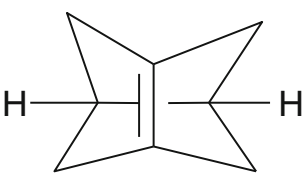

1

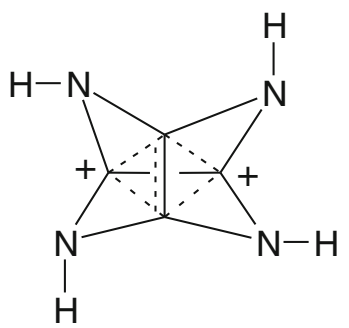

$7 \mathbf{a}$

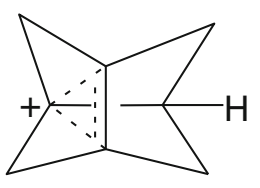

4

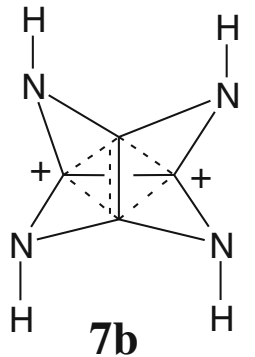

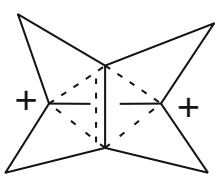

5

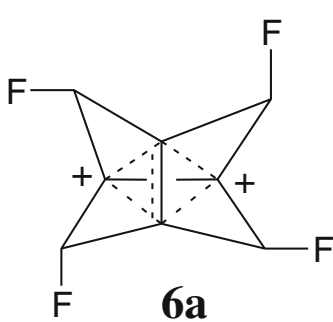

6a

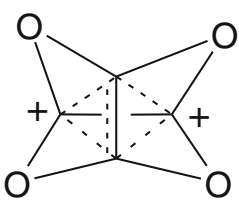

8

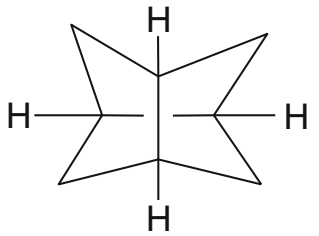

9
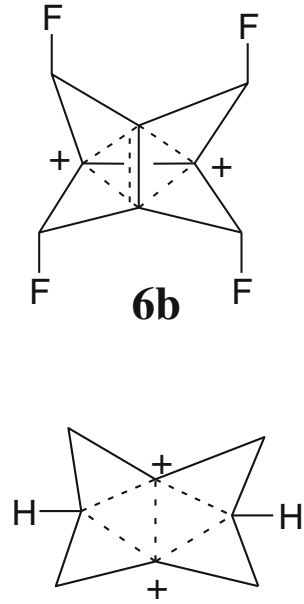

10

Scheme 3 Planar structures of the studied molecules $\mathbf{1}$ and 4-10

10. In Scheme 3, the dashed lines represent multicenter bonding. Structures $6-\mathbf{8}$ were included in order to check the effects of the presence of some electron-withdrawing substituents on the bonding scheme.

Figure 1 shows the optimized geometries of the studied species $\mathbf{1}, \mathbf{4 - 7 , 9}$, and $\mathbf{1 0}$, as well as selected bond lengths and interatomic distances (in $\AA$ ). All studied species were minima on the potential energy surface.

The $\mathrm{C} 3-\mathrm{C} 4$ bond in bisnoradamantene $\mathbf{1}(1.668 \AA)$ is longer than the length of a conventional single $\mathrm{C}-\mathrm{C}$ bond $(\sim 1.55 \AA)$. The $\mathrm{C} 3-\mathrm{C} 4$ bond in $\mathbf{1}$ in its singlet state is even longer than that of the corresponding bond in bisnoradamantene in a triplet state: $1.635 \AA$ (see the "Electronic supplementary material," ESM).

In the monocation $\mathbf{4}$ and dication $\mathbf{5}$, carbon atoms 1,2 , and 4 in $\mathbf{4}$ and 1-4 in 5 are supposedly involved in the multicenter bonding. Upon going from the neutral species 1 to the cation $\mathbf{4}$ and then to the dication $\mathbf{5}$, the $\mathrm{C} 1-\mathrm{C} 2$ bond length increases from that of a typical double bond (in 1) to nearly a single bond length (in 5). This suggests a decrease in the $\pi$-bonding on going from the neutral molecule $\mathbf{1}$ to the dication 5. Conversely, the $\mathrm{C} 3-\mathrm{C} 4$ interatomic distance decreases from $\mathbf{1}$ to $\mathbf{5}$ (Fig. 1). Accordingly, the interatomic distance between the $\mathrm{C} 1$ and $\mathrm{C} 4$ atoms in $\mathbf{4}$ and in $\mathbf{5}$ is shorter than it is in $\mathbf{1}$. As a consequence, the atomic pairs $\mathrm{C} 1-\mathrm{C} 4$ and $\mathrm{C} 2-\mathrm{C} 4$ in 4 and $\mathrm{C} 1-\mathrm{C} 4, \mathrm{C} 1-\mathrm{C} 3, \mathrm{C} 2-\mathrm{C} 3$, and $\mathrm{C} 2-\mathrm{C} 4$ in $\mathbf{5}$ probably have stronger chemical interactions than those in $\mathbf{1}$. These statements are also supported by their corresponding DIs (Table 1).

The tetrafluoro-substituted dication $\mathbf{6 a}$ is $11.8 \mathrm{kcal} \mathrm{mol}^{-1}$ (as calculated at the B3LYP/6-311++g(d,p) level) lower in energy than its isomer $\mathbf{6 b}$. The $\mathrm{C} 1-\mathrm{C} 2$ bond length is basically the same in $\mathbf{6 a}$ and $\mathbf{6 b}$. The $\mathrm{C} 3-\mathrm{C} 4$ bond length is slightly shorter in $\mathbf{6 a}$ than in $\mathbf{6 b}$ and $\mathbf{5}$. According to the inverse relation between bond length and bond strength, there is a stronger interaction between the $\mathrm{C} 3$ and $\mathrm{C} 4$ atoms in $\mathbf{6 a}$ than in $\mathbf{6 b}$, which is supported by the corresponding DI values, which are 1.055 for $\mathrm{C} 3-\mathrm{C} 4$ in $\mathbf{6 b}$ and 1.079 for C3-C4 in 6a.

In species 7 and 8 , there are nitrogen ( $7 \mathbf{a}$ and $7 \mathbf{b})$ and oxygen (8) atoms instead of methylene groups. Species 7a has a longer $\mathrm{C} 1-\mathrm{C} 2$ bond and a shorter $\mathrm{C} 3-\mathrm{C} 4$ bond than those in $7 \mathbf{b}$, which indicates higher $\pi$-bond participation in $\mathbf{7} \mathbf{a}$. In addition, $7 \mathbf{a}$ is lower in energy than $7 \mathbf{b}\left(\Delta G_{7 \mathbf{a}-7 \mathbf{b}}=10.4 \mathrm{kcal} \mathrm{mol}^{-1}\right.$, as calculated at the B3LYP/6-311++G** level).

Figure 2 shows the $(3,-3)$ critical points of the Laplacians of the charge density [43] for $\mathbf{7 a}$ and $\mathbf{7 b}$. Each critical point represents the point at which the highest concentration of charge density occurs in the bonding region [41]. It also represents an unshared electron pair, as seen for the nitrogen atoms in $\mathbf{7 a}$ and $\mathbf{7 b}$. All four unshared electron pairs in $\mathbf{7 b}$ have an upward orientation, while two of the unshared electron pairs in 7a have a downward orientation and the others have an upward orientation. The energy of the nitrogen $(-55.1215$ a.u.) in $7 \mathbf{a}$ is higher than its corresponding value in $7 \mathbf{b}\left(E_{\mathrm{N}}=-55.1345\right.$ a.u.). This information implies that the unshared electron pairs in 7a interact with all of the positively charged $\mathrm{C}$ atoms to some extent, while the unshared electron pairs in $\mathbf{7 b}$ only interact with two positively charged $\mathrm{C}$ atoms (Fig. 2), which may be responsible for the smaller energy of the isomer $7 \mathbf{a}$.

The interatomic distances between the $\mathrm{C} 1$ and $\mathrm{C} 4$ atoms and the $\mathrm{C} 3$ and $\mathrm{C} 4$ atoms in $\mathbf{6}, \mathbf{7}$, and $\mathbf{8}$ are smaller than those in $\mathbf{1}$, except for the $\mathrm{C} 3-\mathrm{C} 4$ interatomic distance in $\mathbf{7 b}$. This indicates that the bisnoradamatenyl dication derivatives $\mathbf{6 , 7}$, and $\mathbf{8}$ show stronger chemical interactions in the atomic 


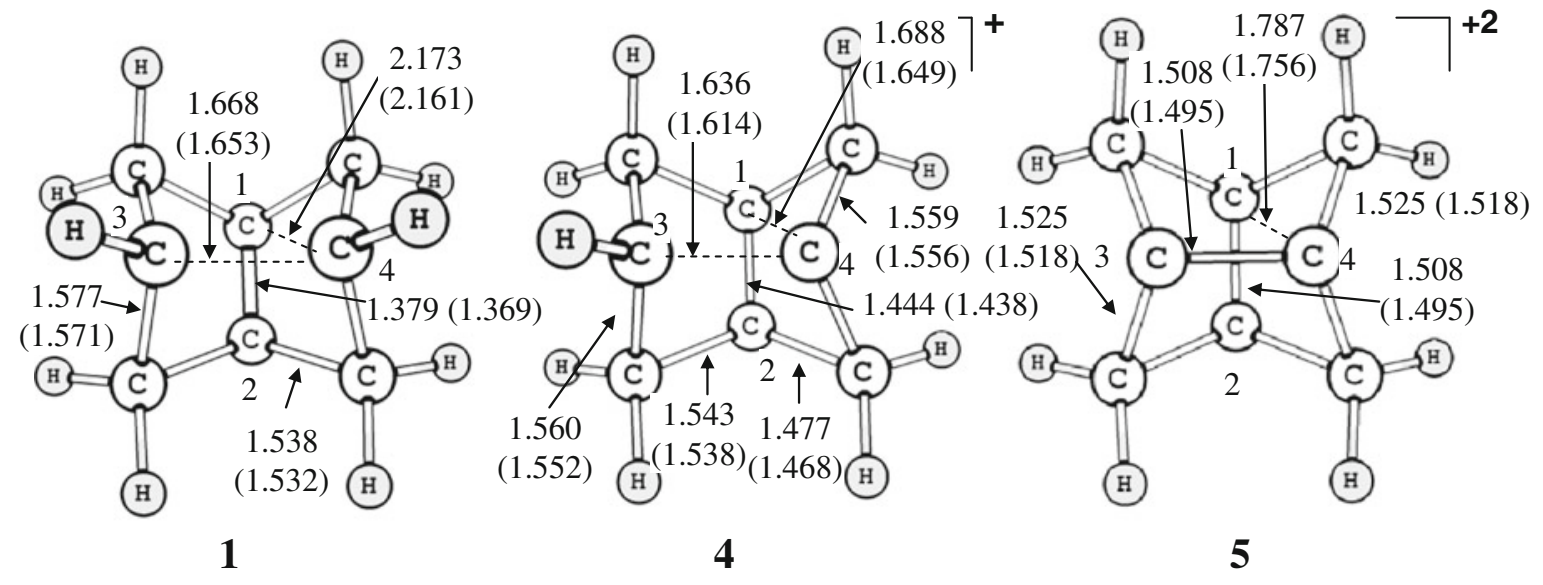

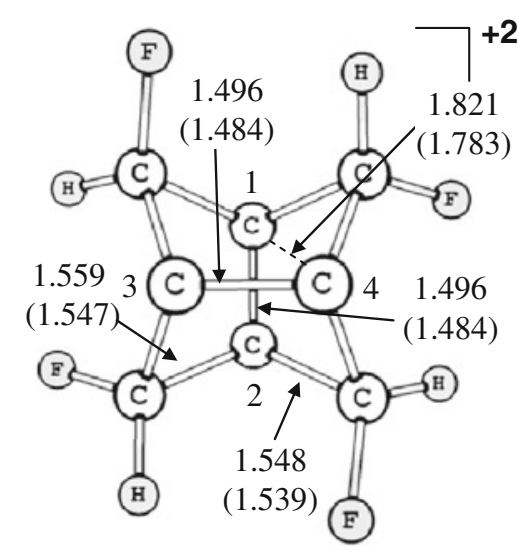

$6 a$

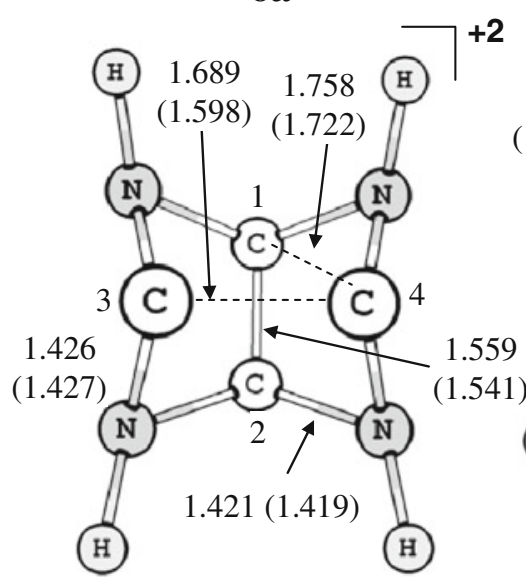

7b

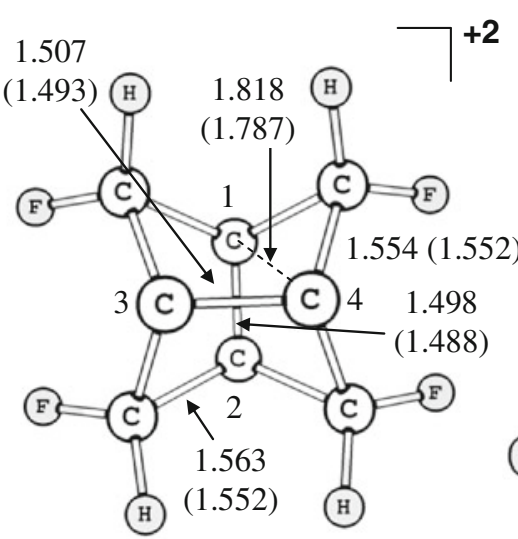

6b

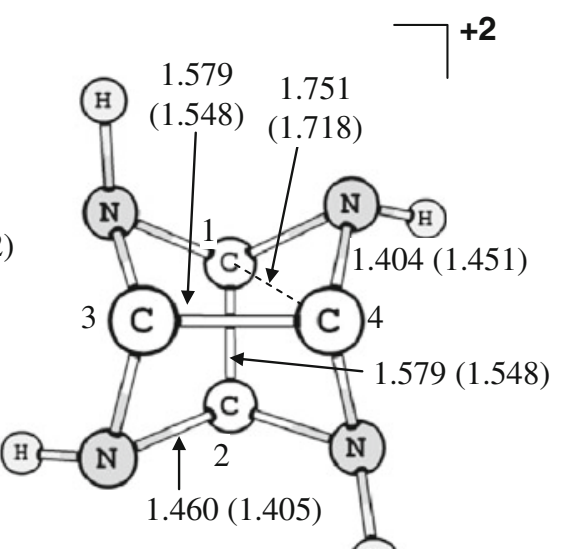

$7 a$

(H)

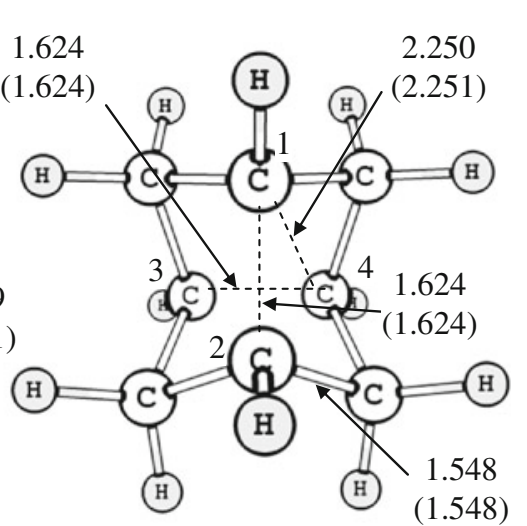

9

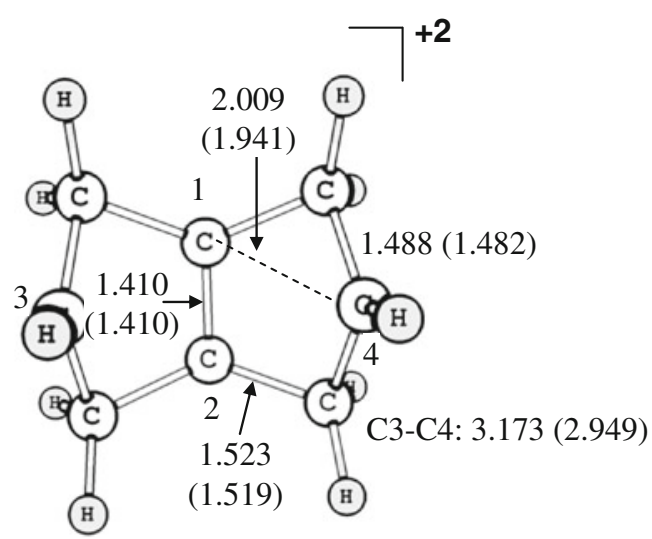

10

Fig. 1 Geometries of the species 1, 4-7, 9, and 10, as well as $\mathrm{C}-\mathrm{C}$ bond lengths and interatomic distances (in $\AA$ ) for them, as obtained at the $\mathrm{B} 3 \mathrm{LYP} / 6-311++\mathrm{G}^{* *}$ and M06-2X/6-311++G** (values in parentheses) levels of theory. Dashed lines represent the interatomic distances

pairs $\mathrm{C} 3-\mathrm{C} 4, \mathrm{C} 1-\mathrm{C} 4, \mathrm{C} 1-\mathrm{C} 3, \mathrm{C} 2-\mathrm{C} 3$, and $\mathrm{C} 2-\mathrm{C} 4$ than the corresponding pairs do in $\mathbf{1}$, except for the $\mathrm{C} 3-\mathrm{C} 4$ interaction in $\mathbf{7 b}$, probably because of the multicenter bonding that occurs in these derivatives.

In bisnoradamantane 9 , the $\mathrm{C} 1-\mathrm{C} 2$ and $\mathrm{C} 3-\mathrm{C} 4$ bonds are slightly shorter $(1.624 \AA)$ than the $\mathrm{C} 3-\mathrm{C} 4$ bond in $\mathbf{1}$ and longer than a conventional single $\mathrm{C}-\mathrm{C}$ bond. Their bond orders $(n)$ are smaller than that of a conventional $\mathrm{C}-\mathrm{C}$ bond (Table 2). Bisnoradamantane and bisnoradamantene have neither multicenter bonding nor a cationic center to attract bonding electrons, unlike in $\mathbf{4}$ and $\mathbf{5}$. Bonding electrons in $\mathbf{1}$ and $\mathbf{9}$ are therefore more localized than those in $\mathbf{4}$ and $\mathbf{5}$. The 


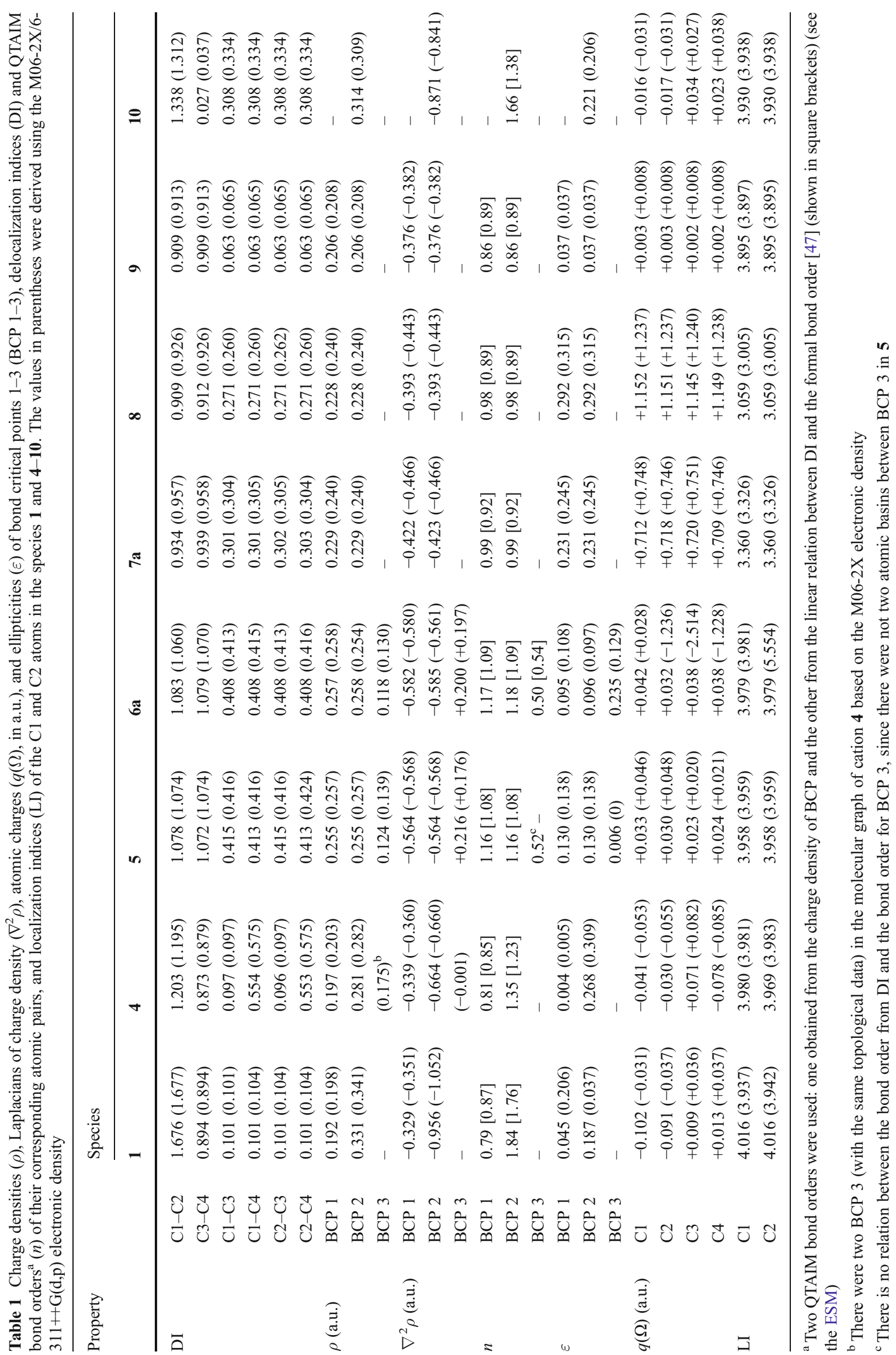



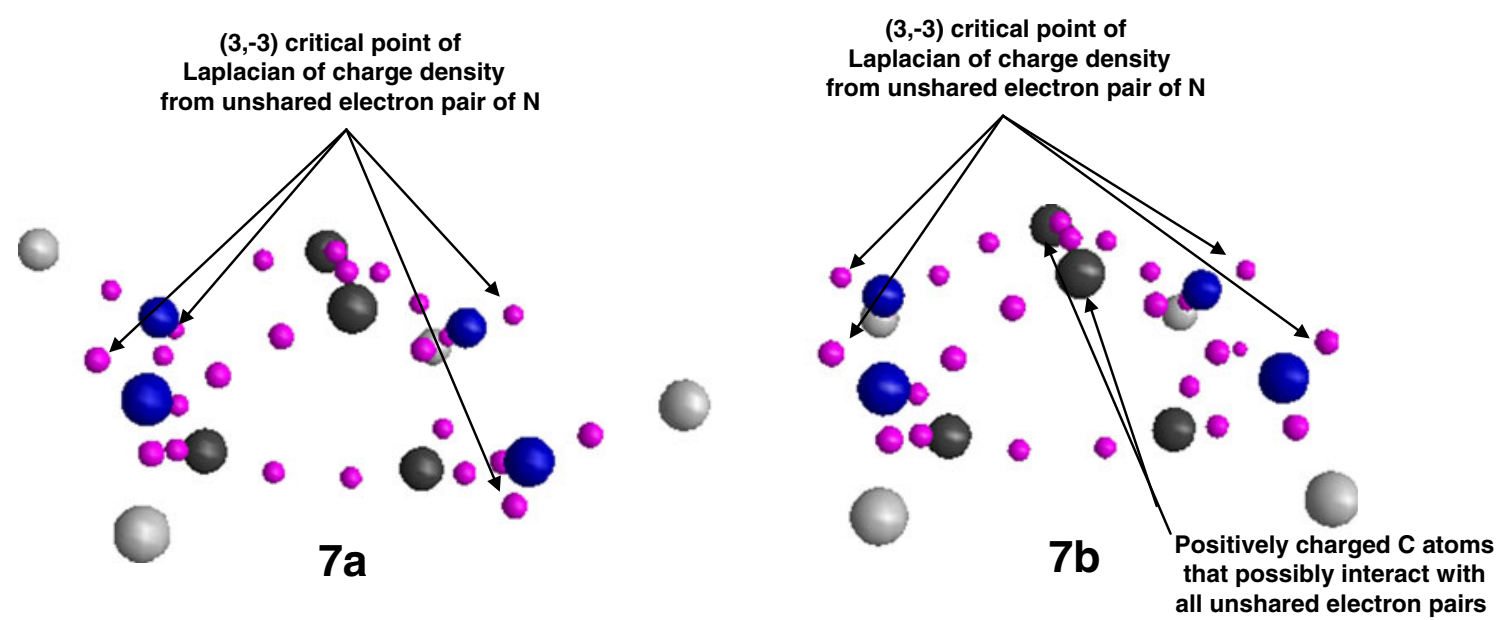

Fig. $2(3,-3)$ critical points of the Laplacians of charge density for $\mathbf{7 a}$ and $\mathbf{7 b}$

increased localization of the $\mathrm{C} 1-\mathrm{C} 2$ and $\mathrm{C} 3-\mathrm{C} 4$ bonding electrons possibly yields greater electronic repulsion among their respective electrons. In comparison with the stable molecule tetra-t-butyl-tetrahedrane (which has a cage with similar "intersecting" $\mathrm{C}-\mathrm{C}$ bonds), the cage structures of $\mathbf{1}$ and $\mathbf{9}$ are less rigid due to the presence of more atoms in the cage, yielding a higher degree of freedom. We can then infer that this less rigid cage structure of $\mathbf{1}$ and $\mathbf{9}$ allows $\mathrm{C} 3-\mathrm{C} 4$ and $\mathrm{C} 1-\mathrm{C} 2$ to lengthen in comparison to single $\mathrm{C}-\mathrm{C}$ bonds, thus decreasing the electronic repulsion between these "intersecting" bonds.

In the dication 10, the length of the $\mathrm{C} 1-\mathrm{C} 2$ bond lies between those of a single and a double bond, and the $\mathrm{C} 3-\mathrm{C} 4$ interatomic distance $(3.173 \AA$ Á) indicates ring opening. This is somewhat expected, since there is no geometric or electronic effect that could decrease the intramolecular chargecharge repulsion.

Figure 3 shows molecular graphs of bisnoradamantene 1 and the bisnoradamantenyl cation $\mathbf{4}$ and dication $\mathbf{5}$ according to the $\mathrm{B} 3 \mathrm{LYP} / 6-311++\mathrm{G}(\mathrm{d}, \mathrm{p})$ electronic density, depicting the bond critical points $1-3$ (BCP 1-3), as well as a molecular graph of 4 based on the M06-2X/6-311++G(d,p)calculated electronic density. Each molecular graph is represented by bond paths and by critical points of the gradient of charge density $(\nabla \rho)$. Except for 4 , the pair of molecular graphs obtained from the M06-2X/6-311++G(d,p)-calculated and B3LYP/6-311++G(d,p)-calculated electronic densities for each molecule are homeomorphic [44]. The bond paths and the topological values associated with the bond critical point (BCP) are used to evaluate the nature and strength of a chemical bond or interatomic interaction [41, $45,46]$.

According to the QTAIM analysis of dication 5, there are two bond paths linking BCP 1, BCP 2, and BCP 3 . Only species $\mathbf{6 a}$ and $\mathbf{6 b}$ have the same bond paths where BCP 3 is located. On the other hand, QTAIM analysis of the electronic density obtained from the M06-2X functional shows that the bisnoradamantenyl cation 4 has two more bond paths involving the $\mathrm{C} 1, \mathrm{C} 2$, and $\mathrm{C} 4$ atoms besides that linking $\mathrm{C} 1$ and $\mathrm{C} 2$. These bond paths (BCP 2 and 3) in bisnoradamantenyl cation 4 indicate a $3 c-2 e$ bonding system involving the $\mathrm{C} 1, \mathrm{C} 2$, and $\mathrm{C} 4$ atoms. As a consequence, the $3 \mathrm{c}-2 \mathrm{e}$ bonding scheme in 4 , as calculated using the M06-2X functional, is stronger than that calculated using the B3LYP functional for the same species, as also observed from the higher DI values of the $\mathrm{C} 4-\mathrm{C} 2$ and $\mathrm{C} 4-\mathrm{C} 1$ atomic pairs based on the M06-2X/ 6-311++G(d,p)-calculated electronic density (see Table 1).
Table 2 Average DIs (based on $\mathrm{C} 1-\mathrm{C} 2, \mathrm{C} 3-\mathrm{C} 4, \mathrm{C} 1-\mathrm{C} 3, \mathrm{C} 1-\mathrm{C} 4$, $\mathrm{C} 2-\mathrm{C} 3$, and $\mathrm{C} 2-\mathrm{C} 4)$, the corresponding mean deviations $(\sigma)$ and DIUs, the degrees of degeneracy $(\delta)$ involving the $\mathrm{C} 1-\mathrm{C} 4$ atomic energies, ring density factors, and the NICS values of the molecules $\mathbf{1 , 4}, \mathbf{5}$, 6a, $7 \mathbf{a}, 8$, and 9

\begin{tabular}{llllllll}
\hline Species & Average DI & $\sigma$ & DIU & $\delta$ & RDF & D3BIA & NICS (ppm) \\
\hline $\mathbf{1}$ & 0.496 & 0.526 & -6.174 & 0.5 & 0.048 & -0.1 & -3.25 \\
$\mathbf{4}$ & 0.570 & 0.315 & 44.694 & 0.5 & 0.080 & 1.8 & -28.52 \\
$\mathbf{5}$ & 0.659 & 0.276 & 54.061 & 1 & 0.136 & 7.3 & -54.13 \\
$\mathbf{6 a}$ & 0.631 & 0.289 & 54.177 & 1 & 0.131 & 7.1 & -48.92 \\
$\mathbf{7 a}$ & 0.522 & 0.290 & 44.420 & 1 & 0.142 & 6.3 & -53.21 \\
$\mathbf{8}$ & 0.482 & 0.296 & 38.678 & 1 & 0.152 & 5.9 & -41.49 \\
$\mathbf{9}$ & 0.348 & 0.377 & -8.405 & 1 & 0.038 & -0.3 & -9.24 \\
\hline
\end{tabular}




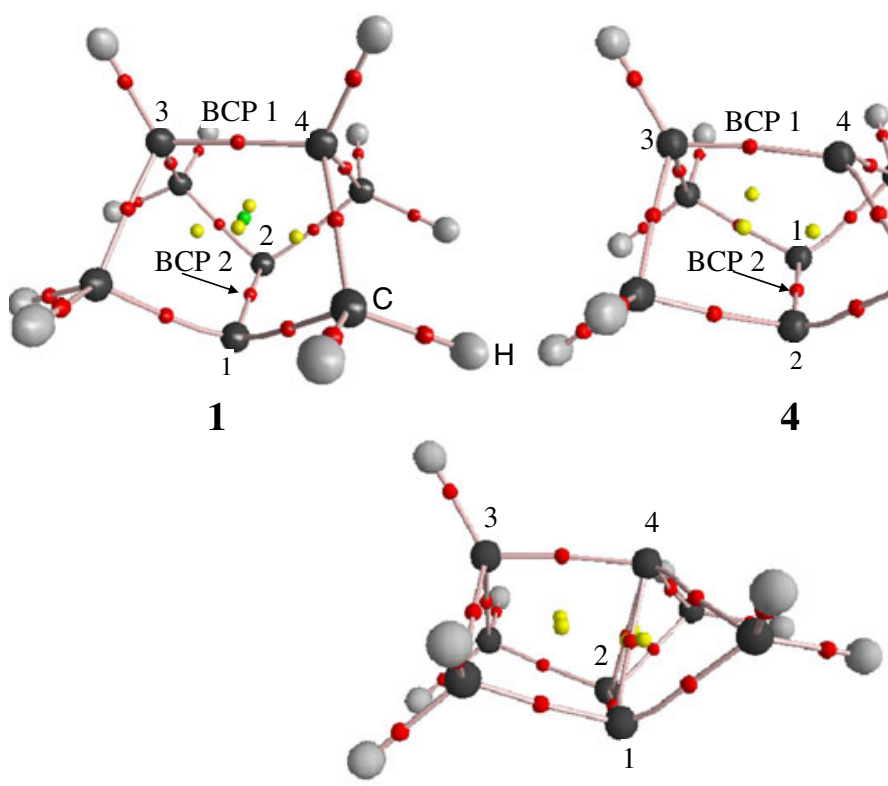

4 (M06-2X)

Fig. 3 Molecular graphs of bisnoradamantene 1 and the bisnoradamantenyl cation $\mathbf{4}$ and dication 5 according to the B3LYP/6-311++G(d, p)-calculated electronic density, and a molecular graph of the bisnoradamantenyl cation 4 based on the M06-2X/6-311++G(d,p)-calculated electronic density. The molecular graph for the latter is shown twice

Table 1 shows important topological information for atoms $\mathrm{C} 1$ to $\mathrm{C} 4$ and their corresponding bond critical points in the species $\mathbf{1}$ and 4-10 obtained using both the B3LYPand the M06-2X-calculated electron densities: delocalization index (DI), charge density of the bond critical point $(\rho)$, QTAIM atomic charge $[q(\Omega)]$, Laplacian of the charge density of the bond critical point $\left(\nabla^{2} \rho\right)$, QTAIM formal bond order $(n)$, localization index (LI), and ellipticity of a chemical bond $(\varepsilon)$.

Analysis of the topological information for all studied species in Table 1 indicates that very similar results are obtained regardless of whether the electron density is calculated using B3LYP or M06-2X.

In bisnoradamantene $\mathbf{1}$, the bond orders and corresponding DI values of the $\mathrm{C} 1-\mathrm{C} 2$ and $\mathrm{C} 3-\mathrm{C} 4$ bonds are smaller than those of conventional double and single bonds, respectively [47]. In addition, there are moderate DI values for the $\mathrm{C} 1-\mathrm{C} 3$, $\mathrm{C} 1-\mathrm{C} 4, \mathrm{C} 2-\mathrm{C} 3$, and $\mathrm{C} 2-\mathrm{C} 4$ atomic pairs, which indicate that each of these atomic pairs has a moderate interaction strength. These moderate interatomic interactions are not characteristic of neutral alkenes, but bisnoradamantene 1 may be an exception, perhaps due to geometric constraints arising from its highly pyramidalized angle $\left(\Phi=72.4^{\circ}\right)$.

In this work, two QTAIM bond orders were used for comparison purposes: one obtained from the BCP charge density $[48,49]$ and the other from the linear relation between DI and the formal bond order [47] (see the ESM). The values of these QTAIM bond orders were very similar (Table 1).

In cation 4, there are reasonable values of DI for the atomic pairs $\mathrm{C} 1-\mathrm{C} 4$ and $\mathrm{C} 2-\mathrm{C} 4$. These DI values are similar to the set of DIs observed for a multicenter bonding system $[38,40]$. This suggests a $3 \mathrm{c}-2 \mathrm{e}$ bond involving the $\mathrm{C} 1, \mathrm{C} 2$, and $\mathrm{C} 4$ atoms in $\mathbf{4}$.

In dication 5, both the $\mathrm{C} 1-\mathrm{C} 2$ and the $\mathrm{C} 3-\mathrm{C} 4$ bonds have the same DI and bond order values. The bond orders of $\mathrm{C} 1-$ $\mathrm{C} 2$ and $\mathrm{C} 3-\mathrm{C} 4$ are slightly higher than that of a single bond. The corresponding DIs also are slightly higher than that of a single $\mathrm{C}-\mathrm{C}$ bond (see the ESM). The values of the charge density, the Laplacian of the charge density, and the ellipticities of BCPs 1 and 2 also are similar. The value of $\rho$ for BCP 3 is not negligible (it is half the value of a single $\mathrm{C}-\mathrm{C}$ bond), although its $\nabla^{2} \rho$ value indicates charge depletion, and there is no corresponding BCP 3 in the virial graph of 5, which means that the atomic interaction line that passes through BCP 3 in the molecular graph of $\mathbf{5}$ is not a bond path (ESM). For the valence shell charge concentration (VSCC) of dication $\mathbf{5}$, no $(3,-3)$ critical point of the Laplacian of the charge density (the absolute maximum concentration of the charge density) was found between the $\mathrm{C} 1-\mathrm{C} 2$ and $\mathrm{C} 3-\mathrm{C} 4$ bonds (Fig. 3). However, the set of DIs for the atomic pairs $\mathrm{C} 1-\mathrm{C} 3, \mathrm{C} 1-\mathrm{C} 4$, $\mathrm{C} 2-\mathrm{C} 3$, and $\mathrm{C} 2-\mathrm{C} 4$ are similar to those for a multicenter bonding system, thus suggesting the existence of a $4 \mathrm{c}-2 \mathrm{e}$ bonding system in $\mathbf{5}$ [38-40]. 
The DI of the C1-C2 bond and the corresponding charge density of BCP 2 decrease from neutral compound 1 to the dication species $\mathbf{5}$. Accordingly, the bond order of the $\mathrm{C} 1-\mathrm{C} 2$ bond and the charge density concentration of the $\mathrm{C} 1-\mathrm{C} 2 \mathrm{BCP}$, BCP 2, also decrease (the charge density concentration decreases as the value of $\nabla^{2} \rho$ becomes less negative). Conversely, the DI of the $\mathrm{C} 3-\mathrm{C} 4$ bond and the charge density of the C3-C4 BCP, BCP 1, increase from 1 to $\mathbf{5}$ (Table 1). This indicates a simultaneous increase in $\mathrm{C} 1-\mathrm{C} 2 \pi$-bond interaction with bridgehead carbon atom (in 1) or corresponding charged carbon atom (in 4 and 5) and an increase in the $\mathrm{C} 3-$ C4 interatomic interaction on going from $\mathbf{1}$ to $\mathbf{4}$ and to $\mathbf{5}$, probably due to the increase in molecular charge on changing from a neutral species to a monocation and then to a dication.

In bisnoradamantene $\mathbf{1}$, the $\mathrm{C} 1$ and $\mathrm{C} 2$ atoms have negative charges while the $\mathrm{C} 3$ and $\mathrm{C} 4$ atoms have small positive charges. Accordingly, the localization index (LI) values (the number of localized electrons) of the $\mathrm{C} 1$ and $\mathrm{C} 2$ atoms decrease from 1 to 5 (Table 1). The increased localization of electrons on the $\mathrm{C} 1$ and $\mathrm{C} 2$ atoms in $\mathbf{1}$ is due to the potential diradical character of its $\mathrm{C} 1=\mathrm{C} 2$ double bond. From Table 1, we can see that the negative charges on the $\mathrm{C} 1$ and $\mathrm{C} 2$ atoms decrease from $\mathbf{1}$ to $\mathbf{4}$ and then to $\mathbf{5}$. Besides, in cation $\mathbf{4}$, the $\mathrm{C} 1, \mathrm{C} 2$, and $\mathrm{C} 4$ atoms are negatively charged while the C3 atom is positively charged, whereas in dication $\mathbf{5}$, all of the bridgehead carbon atoms are positively charged, as expected.

In the tetrafluoro-substituted dications $\mathbf{6 a}$ and $\mathbf{6 b}$, there are four electron-withdrawing substituents: one fluorine atom is bonded to each carbon atom vicinal to the $\mathrm{C} 1-\mathrm{C} 4$ atoms. However, the values of DI, $\rho$, and the formal bond order $(n)$ of $\mathbf{6 a}$ are very close to those of dication $\mathbf{5}$ (Table 1), which can be accounted for by noting that (according to its Hammett substituent constant) fluorine is not such a strong electronwithdrawing group in the para position $\left(\sigma_{\mathrm{p}}=0.06\right)$. Indeed, other related substituent constants of fluorine $\left(\sigma^{+}=-0.07\right.$; $\sigma^{-}=-0.03 ; \sigma_{\mathrm{R}}=-0.48$ ) [50] may indicate an opposing electron-donating effect arising through resonance effects. In addition, the molecular graph and virial paths of $\mathbf{6 a}$ are similar to those of 5 (Fig. 4 and the ESM). As a consequence, the strengths of the interatomic interactions involving the $\mathrm{C} 1, \mathrm{C} 2$, $\mathrm{C} 3$, and $\mathrm{C} 4$ atoms in $\mathbf{6 a}$ are comparable to those of the corresponding interactions in dication $\mathbf{5}$.

On the other hand, in species 7a and $\mathbf{8}$, all of the DI values involving the $\mathrm{C} 1-\mathrm{C} 4$ atoms and the charge densities in BCP 1 and BCP 2 are smaller than those in 5. Thus, the chemical interactions involving the $\mathrm{C} 1, \mathrm{C} 2, \mathrm{C} 3$, and $\mathrm{C} 4$ atoms in $7 \mathbf{a}$ and $\mathbf{8}$ are weaker than those in $\mathbf{5}$. This is expected, as $7 \mathbf{a}$ and $\mathbf{8}$ have electronegative nitrogen and oxygen atoms, respectively, rather than the methylene groups present in dication $\mathbf{5}$.

Although species $\mathbf{6 a}, 7 \mathbf{a}$, and $\mathbf{8}$ have electronegative atoms instead of hydrogen or methylene groups, topological differences between $\mathbf{6 a}$ and $7 \mathbf{a} / \mathbf{8}$ can be ascribed to the fact that the fluorine atom in $\mathbf{6 a}$ is two bonds away from the $\mathrm{C} 1-$ $\mathrm{C} 4$ atoms, while the nitrogen and oxygen atoms (respectively) in $7 \mathbf{a}$ and $\mathbf{8}$ are vicinal to the $\mathrm{C} 1-\mathrm{C} 4$ atoms, so they exert a stronger electron-withdrawing influence on those $\mathrm{C}$ atoms. Moreover, as mentioned above, the fluorine atom is not a strongly electron-withdrawing group. Accordingly, the LI values of the $\mathrm{C} 1$ and $\mathrm{C} 2$ atoms decrease from 6 to 8 .

In bisnoradamantane 9, all topological information is the same for BCPs 1 and 2. The DIs and bond orders of the atomic pairs $\mathrm{C} 1-\mathrm{C} 2$ and $\mathrm{C} 3-\mathrm{C} 4$ are smaller than those of a single $\mathrm{C}-$ $\mathrm{C}$ bond. The DIs of the atomic pairs $\mathrm{C} 1-\mathrm{C} 3, \mathrm{C} 1-\mathrm{C} 4, \mathrm{C} 2-\mathrm{C} 3$, and $\mathrm{C} 2-\mathrm{C} 4(\mathrm{DI}=0.063)$ indicate that the corresponding interatomic interactions are rather weak. Based on these DI values, we can assume that there is no multicenter bonding system involving $\mathrm{C} 1, \mathrm{C} 2, \mathrm{C} 3$, and $\mathrm{C} 4$ in 9.

In the bisnoradamantanyl dication 10, there is no significant interatomic interaction between the $\mathrm{C} 3$ and $\mathrm{C} 4$ atoms because the corresponding DI is very small. In addition, there are no BCPs between them and no corresponding bond path or virial path. Although BCPs are absent from the atomic pairs $\mathrm{C} 1-\mathrm{C} 3, \mathrm{C} 2-\mathrm{C} 3, \mathrm{C} 1-\mathrm{C} 4$, and $\mathrm{C} 2-\mathrm{C} 4$, their DI values are rather high (Table 1). This indicates that there are two multicenter bonding systems in 10: one involving the $\mathrm{C} 1, \mathrm{C} 2$, and $\mathrm{C} 3$ atoms and another involving the $\mathrm{C} 1, \mathrm{C} 2$, and $\mathrm{C} 4$ atoms. Evidence for the existence of these two multicenter bonds is provided by the smaller atomic energies of $\mathrm{C} 3$ and $\mathrm{C} 4$ (-38.0771 a.u.) than those in 9 (-38.0491 a.u.).

Figure 4 shows molecular graphs of the tetrafluorosubstituted dication $\mathbf{6 a}$, the dication species $\mathbf{7 a}, \mathbf{7 b}$, and $\mathbf{8}$, bisnoradamantane $\mathbf{9}$, and the bisnoradamantanyl dication 10. From Figs. 3 and 4 it is clear that only species $\mathbf{1 0}$ does not have a caged structure, since the $\mathrm{C} 3-\mathrm{C} 4$ distance is rather long (Fig. 1).

Figure 5 shows the HOMOs of species 1, 4, and 5 obtained at the MP2/6-311++G** level. The HOMO of dication 5 is spread over the atoms $\mathrm{C} 1-\mathrm{C} 4$. This indicates that species 5 has a $4 \mathrm{c}-2 \mathrm{e}$ bonding system. The HOMO of cation 4 indicates that it has a $3 \mathrm{c}-2 \mathrm{e}$ bonding system. As for species 1, its HOMO indicates that there is no electron delocalization over atoms $\mathrm{C} 1-\mathrm{C} 4$, as expected. The HOMOs of species 1, 4, and $\mathbf{5}$ are in accord with the topological data, which indicate that there is no multicenter bonding system in $\mathbf{1}$, there is a $3 \mathrm{c}-2 \mathrm{e}$ bonding system in $\mathbf{4}$, and there is a $4 \mathrm{c}-2 \mathrm{e}$ bonding system in $\mathbf{5}$, respectively.

The QTAIM and MO results indicate the existence of the bisnoradamantenyl cation and the bisnoradamantenyl and bisnoradamantanyl dications; the present work represents the first report of these novel carbonium ions.

As previously noted, topological and molecular orbital evaluations of species $\mathbf{4}$ and $\mathbf{5}$ and topological evaluations of dications $6 \mathbf{a}, 7 \mathbf{a}$, and 8 indicate that these species have $3 \mathrm{c}-2 \mathrm{e}$ or 4c-2e multicenter bonding systems, which obey Huckel's rule. Moreover, the corresponding interatomic distances 


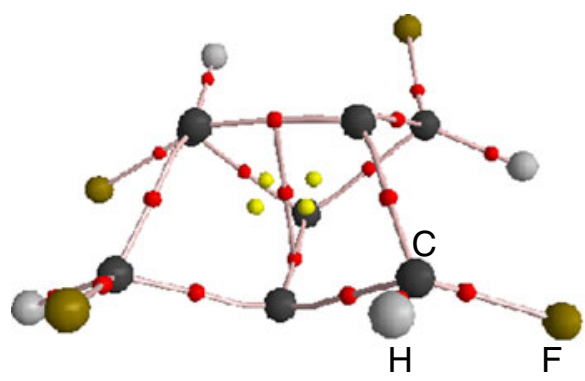

$6 a$

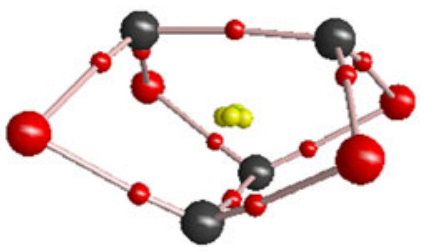

8
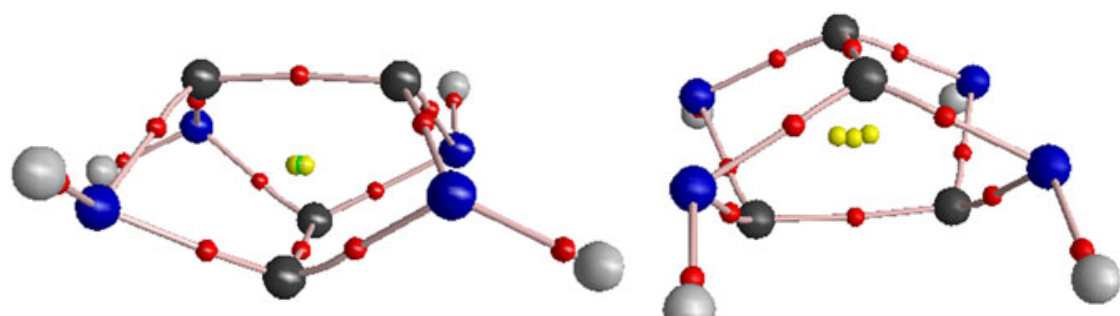

$7 b$

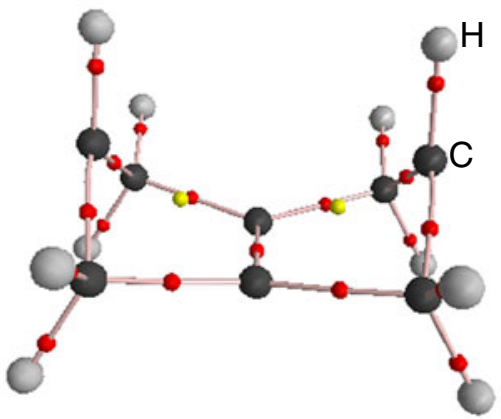

10

Fig. 4 Molecular graphs of the tetrafluoro-substituted dication $\mathbf{6 a}$, the dication species $\mathbf{7 a}, \mathbf{7 b}$, and $\mathbf{8}$, bisnoradamantane $\mathbf{9}$, and the bisnoradamantanyl dication 10, derived based on the B3LYP/6-311++G(d,p)-calculated electronic density

obey the geometric criterion for homoaromatic species. As a consequence, we investigated the homoaromatic character of each of these molecules using two aromaticity indices: NICS [51] and D3BIA (see Table 2).
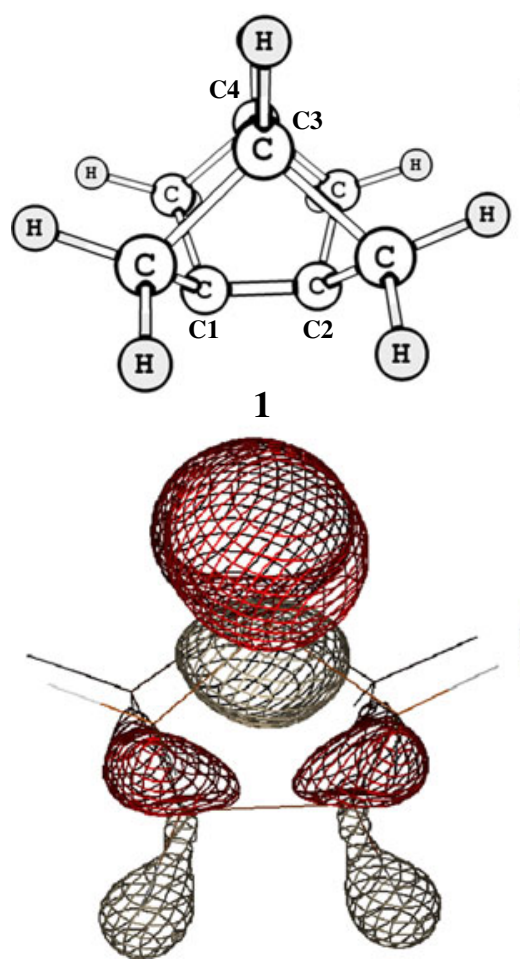

(H)
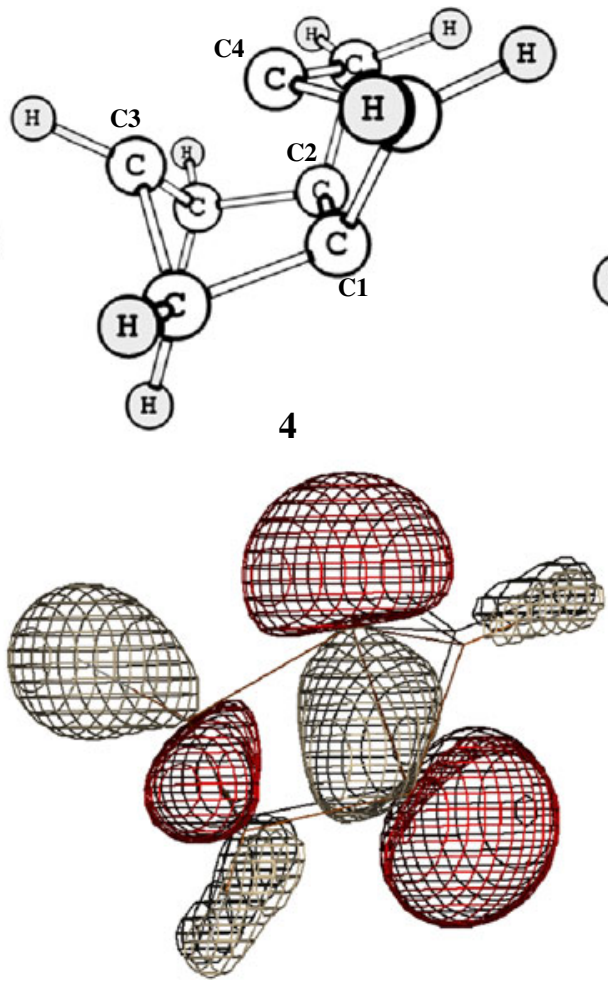

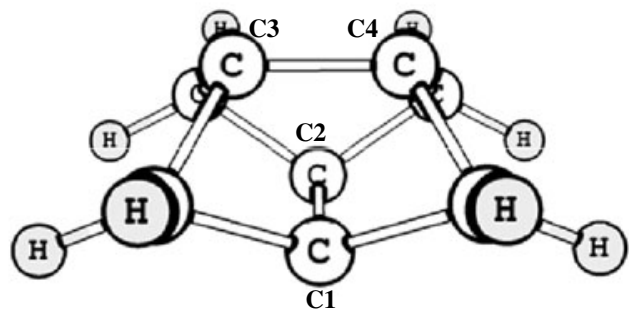

5

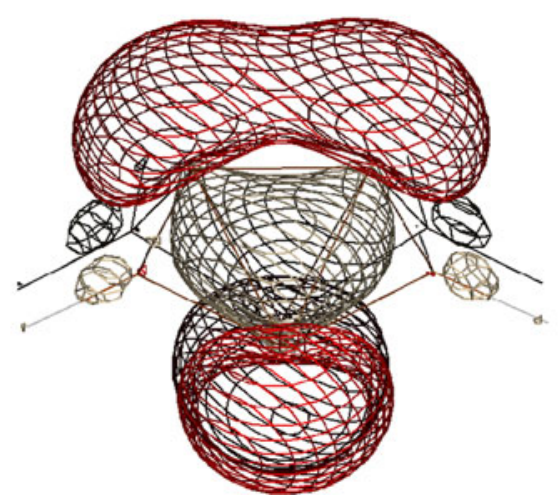

Fig. 5 HOMOs of the species 1, 4, and 5, calculated at the MP2/6-311++G** level 
Table 2 shows the quantities associated with the D3BIA index, along with values for the two aromaticity indices D3BIA and NICS. We did not calculate D3BIA and NICS for species 10 since its molecular graph does not have a caged structure. The aromaticity indices in Table 2 indicate that compounds $\mathbf{1}$ and $\mathbf{9}$ are not aromatic molecules, since their NICS values are close to zero and their D3BIA values are less than zero. Their negative D3BIA values derive from their negative DIU values; DIU is not negative for any aromatic molecule because the average DI (from the DIU formula) is known to be higher than the corresponding mean deviation for all aromatic molecules studied [39].

The D3BIA and NICS values of species $\mathbf{4}$ are the smallest positive and the smallest negative values, respectively, among the studied aromatic species, so this is the least homoaromatic species. A possible reason for this is that monocation $\mathbf{4}$ has a less symmetrical geometry than the other dication species, although it does have a $3 \mathrm{c}-2 \mathrm{e}$ bonding system.

According to the results in Table 2, dication $\mathbf{5}$ is the most homoaromatic species, since it has the highest D3BIA value and the most negative NICS value. Upon analyzing the D3BIA and NICS values of $\mathbf{6 a}, 7 \mathbf{a}$, and $\mathbf{8}$, it is clear that species $\mathbf{8}$ is the least homoaromatic. This may be attributed to the strong inductive effect of the oxygen atoms that are directly bonded to atoms $\mathrm{C} 1-\mathrm{C} 4$ in $\mathbf{8}$, which reduces the electronic density on these $\mathrm{C}$ atoms when compared to those in species $\mathbf{5}$, yielding smaller localization indices for $\mathrm{C} 1$ and $\mathrm{C} 2$ in $\mathbf{8}$ with respect to those in $\mathbf{5}$ (Table 1). Likewise, according to the D3BIA values, when the electronic density at the aromatic site is decreased, the aromaticity also decreases; the NICS values also show this trend (see Fig. 6).

On the other hand, the inductive effect of the fluorine atoms in $\mathbf{6 a}$ is not as strong as the inductive effect of the oxygen atoms in $\mathbf{8}$ because the fluorine atoms are not directly bonded to the $\mathrm{C} 1-\mathrm{C} 4$ atoms in $\mathbf{6 a}$, so the D3BIA and NICS values of these species indicate that $\mathbf{6 a}$ is more homoaromatic than $\mathbf{8}$.

The values of both aromaticity indices are plotted against each other in Fig. 6. This plot shows that there is a good correspondence between D3BIA and NICS, which lends support to the conclusions of our aromaticity analysis based on both D3BIA and NICS.

\section{Conclusions}

QTAIM analysis of the bisnoradamantenyl cation 4 indicates that this species contains a $3 \mathrm{c}-2 \mathrm{e}$ bond involving atoms $\mathrm{C} 1, \mathrm{C} 2$, and $\mathrm{C} 4$. The molecular graph of 4 obtained by calculating the M06-2X/6-311++G(d,p) electronic density also indicates that $\mathbf{4}$ has a $3 \mathrm{c}-2 \mathrm{e}$ bonding system, because there are three BCPs involving the atoms associated with the $3 \mathrm{c}-2 \mathrm{e}$ bonding system. Analysis of the HOMO of $\mathbf{4}$ at the MP2 level leads to the same conclusion.

In the bisnoradamantenyl dication $\mathbf{5}$, there is a $4 \mathrm{c}-2 \mathrm{e}$ bond involving the atoms $\mathrm{C} 1, \mathrm{C} 2, \mathrm{C} 3$, and $\mathrm{C} 4$. Analysis of the HOMO of this species indicates the presence of a $4 c-2 e$ bonding system in this species. Thus, dication 5 presents three-dimensional aromaticity, similar to the 1,3,5,7-dehydroadamantane dication.

QTAIM indicates that $\pi$-bond interaction of $\mathrm{C} 1-\mathrm{C} 2$ with the bridgehead carbon atom increases when going from the neutral species 1 to the cation 4 , and the $\pi$-bond interaction of $\mathrm{C} 3-\mathrm{C} 4$ with the charged carbon atom(s) also increases on going from $\mathbf{4}$ to dication $\mathbf{5}$.

In the bisnoradamantanyl dication $\mathbf{1 0}$, there is no significant chemical interaction between the $\mathrm{C} 3$ and $\mathrm{C} 4$ atoms, but QTAIM analysis indicates that there are two multicenter bonding systems in 10: one involving atoms $\mathrm{C} 1, \mathrm{C} 2$, and $\mathrm{C} 3$ and the other involving atoms $\mathrm{C} 1, \mathrm{C} 2$, and $\mathrm{C} 4$.

QTAIM and MO results point to the existence of the bisnoradamantenyl cation, the bisnoradamantenyl dication, and the bisnoradamantanyl dication, and these carbonium ions are reported here for the first time.

There is a highly linear relationship between the aromaticity indices D3BIA and NICS for these molecules. The values of D3BIA and NICS indicate that dication 5 is the most homoaromatic of these species, that cation $\mathbf{4}$ is the least homoaromatic, and that the homoaromaticity decreases as the electronic density at the aromatic site is reduced.
Fig. 6 Plot of NICS values (in ppm) versus D3BIA values for the molecules $1,4,5,6 \mathbf{a}, 7 \mathbf{a}, 8$, and 9

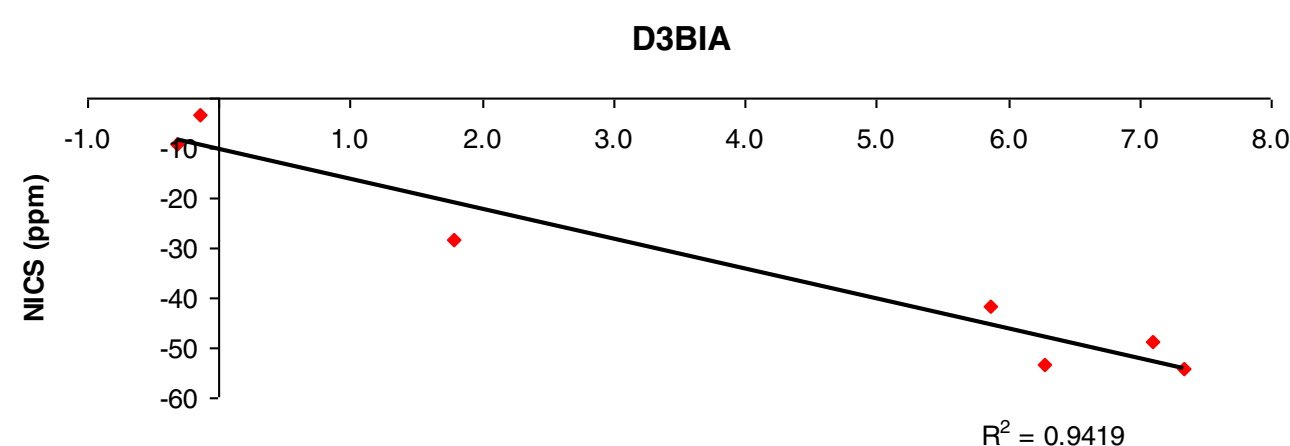

$R^{2}=0.9419$ 
Acknowledgments Authors thank Fundação de Amparo à Pesquisa do Estado do Rio de Janeiro (FAPERJ), Fundação de Amparo à Pesquisa do Estado do Rio Grande do Norte (FAPERN), Coordenação de Aperfeiçoamento de Pessoal de Nível Superior (CAPES), and Conselho Nacional de Desenvolvimento Científico e Tecnológico (CNPq) for financial support.

\section{References}

1. Borden WT (1989) Pyramidalized alkenes. Chem Rev 89:1095-109

2. Vazquez S, Camps P (2005) Chemistry of pyramidalized alkenes. Tetrahedron 61:5147-208

3. Camps P, Luque FJ, Orozco M, Pérez F, Vázquez S (1996) Synthesis, chemical trapping and dimerization of tricyclo[3.3.0.0 $0^{3,7}$ oct-1(5)ene, the consummate member of a series of pyramidalized alkenes. Tetrahedron Lett 37:8605-08

4. Camps P, Font-Bardia M, Pérez F, Solà L, Solans X, Vázquez S (1996) Low temperature X-ray diffraction analysis of 4,5,10,11tetramethyl-heptacyclo $\left[8 \cdot 2 \cdot 1 \cdot 1^{2,5} \cdot 1^{4,7} \cdot 1^{8,11} \cdot 0^{1,8} \cdot 0^{2,7}\right]$ hexadecane: DSC, MM2 and 1H NMR study of its $[2+2]$ retrocycloaddition to an isomeric diene. Tetrahedron Lett 37:8601-04

5. Schleyer PV, Wiskott E (1967) Noradamantane by aluminum halide catalyzed rearrangement. Tetrahedron Lett 2845-2850

6. Wishnok JS, Schleyer PV, Funke E, Pandit GD, Williams RO, Nickon A (1973) Syntheses in noradamantane series. J Org Chem 38:539-42

7. Camps P, Colet G, Delgado S, Munoz AR, Pericas MA, Sola L, Vazquez S (2007) Generation and reactions of new ether and acetal functionalized tricyclo[3.3.0.0(3,7)]oct-1(5)-ene derivatives. DSC and NMR studies on the $[2+2]$ retrocycloaddition of several cyclobutane dimers. Tetrahedron 63:4669-79

8. Camps P, Lukach AE, Vazquez S (2001) Formation and cleavage of bisnoradamantane derivatives through $\mathrm{SmI}_{2}$ reductions. Tetrahedron 57:2419-25

9. Camps P, Munoz MR, Vazquez S (2006) Generation and trapping of tricyclo[3.3.0.0(3,7)]oct-1(5)-ene derivatives containing carbon$\mathrm{yl}$ functionalities. Tetrahedron 62:7645-52

10. Ayats C, Camps P, Font-Bardia M, Munoz MR, Solans X, Vazquez $\mathrm{S}$ (2006) Alternative syntheses of the $\mathrm{D}_{2 \mathrm{~d}}$ symmetric 1,3,5,7-tetraiodotricyclo[3.3.0.0 $\left.0^{3,7}\right]$ octane. Tetrahedron $62: 7436-44$

11. Camps P, Fernandez JA, Font-Bardia M, Solans X, Vazquez S (2005) Diels-Alder reactions of highly pyramidalized tricyclo[3.3.0.0 $(3,7)]$ oct-1(5)-ene derivatives: further chemistry of pentacyclo[6.4.0.0 $(2,10) .0(3,7) .0(4,9)]$ dodeca-5,8,11-triene. Tetrahedron 61:3593-603

12. Camps P, Pujol X, Vazquez S (2002) Synthesis and reactivity of a new functionalized and highly pyramidalized alkene containing the bisnoradamantane skeleton. Tetrahedron 58:10081-86

13. Ayats C, Camps P, Fernandez JA, Vazquez S (2007) Dehalogenation of 1,3-diiodotricyclo[3.3.0.0(3,7)] octane: generation of 1,3-dehydrotricyclo[3.3.0.0(3,7)]octane, a 2,5-methano-bridged[2.2.1]propellane. Chemistry 13:1522-32

14. Theophanous FA, Tasiopoulos AJ, Nicolaides A, Zhou X, Johnson WTG, Borden WT (2006) Evidence for the formation of the $(\mathrm{Ph} 3 \mathrm{P})(2) \mathrm{Pt}$ complex of 3,7-dimethyltricyclo[3.3.0.0 $(3,7)]$ oct-1(5)-ene, the most highly pyramidalized alkene in a homologous series. Isolation and X-ray structure of the product of the ethanol addition to the complex. Org Lett 8:300104

15. Hrovat DA, Borden WT (1988) Ab initio calculations of the olefin strain energies of some pyramidalized alkenes. J Am Chem Soc 110:4710-18
16. Vazquez S (2002) GIAO-DFT study of C-13 NMR chemical shifts of highly pyramidalized alkenes. J Chem Soc Perkin Trans 2:2100-03

17. Camps P, Font-Bardia M, Méndez N, Pérez F, Pujol X, Solans X, Vázquez S, Vilalta M (1998) Highly pyramidalized tricyclo[3.3.0.0 $\left.0^{3,7}\right]$ oct-1(5)-ene and related compounds: high-level ab initio study, synthesis and trapping of tetracyclo $\left[5 \cdot 2 \cdot 1 \cdot 0^{2,6} \cdot 0^{3,8}\right]$ dec-7-ene, and crosscoupling reactions. Tetrahedron 54:4679-96

18. Fernandez JA, S Vazquez (2007) A theoretical study of tricyclo[4.2.1.0(2,5)]non-2(5)-ene, tricyclo[4.2.2.0(2,5)]dec2(5)-ene and related pyramidalized alkenes. Eur J Org Chem 27:4493-98

19. Bremer M, Schleyer PV, Schotz K, Kausch M, Schindler M (1987) 4-Center 2-electron bonding in a tetrahedral topology-experimental realization of 3-dimensional homoaromaticity in the 1,3dehydro-5,7-adamantanediyl dication. Angew Chem Int Ed 26:761-63

20. Herges R, Schleyer PvR, Schindler M, Fessner WD (1991) Tetramethylene dications $\left(\mathrm{Ch}_{2}\right)_{4}{ }^{2+}$ - are the norbornadiene dication, the pagodane dication, and related systems aromatic? J Am Chem Soc 113:3649-56

21. Kroghjespersen K, Cremer D, Dill JD, Pople JA, Schleyer PV (1981) Aromaticity in small rings containing boron and carbon $\left((\mathrm{Ch})_{2}(\mathrm{BH})_{n}, n=1,2\right)$. Comparisons with isoelectronic carbocations. The decisive roles of orbital mixing and nonbonded 1,3interactions in the structures of four-membered rings. J Am Chem Soc 103:2589-94

22. Li X, Frisch MJ (2006) Energy-represented direct inversion in the iterative subspace within a hybrid geometry optimization method. J Chem Theory Comput 2:835-39

23. Pulay P, Fogarasi G (1992) Geometry optimization in redundant internal coordinates. J Chem Phys 96:2856-60

24. Becke AD (1993) Density-functional thermochemistry .3. the role of exact exchange. J Chem Phys 98:5648-52

25. Lee C, Yang W, Parr RG (1988) Development of the Colle-Salvetti correlation-energy formula into a functional of the electron density. Phys Rev B 37:785-89

26. Becke AD (1993) A new mixing of Hartree-Fock and local density-functional theories. J Chem Phys 98:1372-77

27. Zhao Y, Truhlar DG (2008) Density functionals with broad applicability in chemistry. Acc Chem Res 41:157-67

28. Zhao Y, Truhlar DG (2008) The M06 suite of density functionals for main group thermochemistry, thermochemical kinetics, noncovalent interactions, excited states, and transition elements: two new functionals and systematic testing of four M06-class functionals and 12 other functionals. Theor Chem Accounts 120:215-41

29. Gwt MJ, Frisch HB, Schlegel GE, Scuseria MA, Robb JR, Cheeseman G, Scalmani V, Barone B, Mennucci GA, Petersson H, Nakatsuji M, Caricato X, Li HP, Hratchian AF, Izmaylov J, Bloino G, Zheng JL, Sonnenberg M, Hada M, Ehara K, Toyota R, Fukuda J, Hasegawa M, Ishida T, Nakajima Y, Honda O, Kitao H, Nakai T, Vreven JA, Montgomery JE Jr, Peralta F, Ogliaro M, Bearpark JJ, Heyd E, Brothers KN, Kudin VN, Staroverov R, Kobayashi J, Normand K, Raghavachari A, Rendell JC, Burant SS, Iyengar J, Tomasi M, Cossi N, Rega JM, Millam M, Klene JE, Knox JB, Cross V, Bakken C, Adamo J, Jaramillo R, Gomperts RE, Stratmann O, Yazyev AJ, Austin R, Cammi C, Pomelli JW, Ochterski RL, Martin K, Morokuma VG, Zakrzewski GA, Voth P, Salvador JJ, Dannenberg S, Dapprich AD, Daniels Ö, Farkas JB, Foresman JV, Ortiz JC, Fox DJ (2009) Gaussian 09, revision A.01. Gaussian Inc., Wallingford

30. Biegler-König F, Schönbohm J (2002) AIM2000. University of Applied Sciences, Bielefield

31. Biegler-Konig F, Schonbohm J, Bayles D (2001) Software news and updates: AIM2000 - a program to analyze and visualize atoms in molecules. J Comput Chem 22:545-59 
32. Balanarayan P, Gadre SR (2003) Topography of molecular scalar fields. I. Algorithm and Poincaré-Hopf relation. J Chem Phys 119:5037-43

33. Frisch MJ, Head-Gordon M, Pople JA (1990) Semi-direct algorithms for the MP2 energy and gradient. Chem Phys Lett 166:281-89

34. Schleyer PvR, Maerker C, Dransfield A, Jiao H, Hommes NJRvE (1996) Nucleus-independent chemical shifts: a simple and efficient aromaticity probe. J Am Chem Soc 118:6317-18

35. Wolinski K, Hinton JF, Pulay P (1990) Efficient implementation of the gauge-independent atomic orbital method for NMR chemical shift calculations. J Am Chem Soc 112:8251-60

36. Bader RFW, Stephens ME (1975) Spatial localization of the electronic pair and number distributions in molecules. J Am Chem Soc 97:7391-99

37. Bader RFW, Streitwieser A, Neuhaus A, Laidig KE, Speers P (1996) Electron delocalization and the Fermi hole. J Am Chem Soc 118:4959-65

38. Werstiuk NH (2007) 7-Norbornyl cation - fact or fiction? A QTAIMDI-VISAB computational study. J Chem Theor Comput 3:2258-67

39. Firme CL, Antunes OAC, Esteves PM (2008) Electronic nature of the aromatic adamantanediyl ions and its analogues. J Braz Chem Soc 19:140-49

40. Firme CL, Antunes OAC, Esteves PM (2008) Eletronic nature of carbonium ions and their silicon analogues. J Phys Chem A 112:3165-71

41. Bader RFW (1994) Atoms in molecules a quantum theory. Oxford University Press, Oxford
42. Nascimento MAC (2008) The nature of the chemical bond. J Braz Chem Soc 19:245-56

43. Malcolm NOJ, Popelier PLA (2003) The full topology of the Laplacian of the electron density: scrutinising a physical basis for the VSEPR model. Faraday Discuss 124:353-63

44. Keith TA, Bader RFW, Aray Y (1996) Structural homeomorphism between the electron density and the virial field. Int J Quantum Chem 57:183-98

45. Bader RFW (1998) A bond path: a universal indicator of bonded interactions. J Phys Chem A 102:7314-23

46. Bader RFW (2009) Bond paths are not chemical bonds. J Phys Chem A 113:10391-96

47. Firme CL, Antunes OAC, Esteves PM (2009) Relation between bond order and delocalization index of QTAIM. Chem Phys Lett 468:129-33

48. Bader RFW, Tang TH, Tal Y, Biegler-König FW (1982) Molecular structure and its change: hydrocarbons. J Am Chem Soc 104:940-45

49. Bader RFW, Tang TH, Tal Y, Biegler-König FW (1982) Properties of atoms and bonds in hydrocarbon molecules. J Am Chem Soc 104:946-52

50. Hansch C, Leo A, Taft RW (1991) A survey of Hammett substituent constants and resonance and field parameters. Chem Rev 91:165-95

51. Chen ZF, Wannere CS, Corminboeuf C, Puchta R, Schleyer PV (2005) Nucleus-independent chemical shifts (NICS) as an aromaticity criterion. Chem Rev 105:3842-88 